\title{
Gastric epithelial cell kinetics in the progression from normal mucosa to gastric carcinoma
}

\author{
R J Cahill, C Kilgallen, S Beattie, H Hamilton, C O'Morain
}

\begin{abstract}
Increased epithelial cell proliferation is associated with an increased risk of adenocarinoma and is associated with Helicobacter pylori infection. The aim of this study was to assess both gastric epithelial cell proliferation and the influence of $H$ pylori infection on cell kinetics in the progression from normal mucosa to gastric carcinoma. One hundred and forty four subjects were assigned to study groups based on diagnosis and $H$ pylori status: microscopically normal mucosa and $H$ pylori negative $(n=28)$; chronic active gastritis and $H$ pylori positive $(n=83)$; atrophic gastritis $(n=9)$; intestinal metaplasia $(n=19)$; gastric carcinoma $(n=12)$. Gastric antral epithelial cell proliferation was assessed using the in vitro bromodeoxyuridine immunohistochemical technique and expressed as the labelling index per cent $(\mathrm{LI} \%)$. Subjects with chronic atrophic gastritis, intestinal metaplasia or gastric cancer have increased gastric epithelial cell proliferation compared with normal mucosa (LI\% mean (SEM): 5.14 $(0.6), 4.68(0.3), 6.50(0.5)$ v $3.08(0.2)$, $\mathbf{p}<0.001)$. This increase in gastric epithelial cell proliferation was not influenced by $H$ pylori status. Gastritis associated with $H$ pylori had an increased LI\% compared with normal controls or subjects with $H$ pylori negative gastritis $(4.98(0.2) v 3.08$ $(0.2), 3.83(0.2), p<0 \cdot 01)$. H pylori infection although associated with an increased epithelial cell proliferation in subjects with chronic gastritis, does not influence the increased epithelial cell proliferation seen in subjects with precancerous lesions or gastric carcinoma. This is further evidence that $H$ pylori may be an initiating step in gastric carcinogenesis.

(Gut 1996; 38: 177-181)
\end{abstract}

Keywords: gastric carcinogenesis, cell kinetics, Helicobacter pylori.

Although the overall incidence of gastric cancer has steadily declined during the past 50 years in the Western world, it is still a major health problem and it remains the second most common cancer in the world. Gastric cancer has a poor prognosis and in a recent British study the overall five year survival for subjects with resectable gastric cancer was $20 \%{ }^{1}$

The aetiology of gastric carcinoma has not been fully elucidated. In 1988 Correa and colleagues proposed a human model of gastric carcinogenesis based on epidemiological, pathological, and clinical findings. They postulated that gastric cancer develops through a complex sequence of events from normal mucosa to superficial gastritis, chronic atrophic gastritis, intestinal metaplasia, dysplasia, and finally to intestinal type gastric carcinoma. Correa suggested that an environmental agent induced chronic gastritis, the first step in the progression to malignancy. ${ }^{2}$

Helicobacter pylori is associated with a sixfold increased risk of gastric carcinoma. ${ }^{3} \mathrm{H}$ pylori is frequently found in association with gastric cancer and precancerous lesions. ${ }^{45}$ Longterm studies of $H$ pylori infection have provided evidence of a progression from $H$ pylori gastritis to atrophic gastritis, intestinal metaplasia, and dysplasia. ${ }^{6}$

The mechanism by which $H$ pylori participates in gastric carcinogenesis is largely unknown. We have identified an increased gastric epithelial cell proliferation associated with $H$ pylori infection, which is reversed when the organism is eradicated. ${ }^{7}{ }^{8}$ Increased epithelial cell proliferation has been associated with an increased risk of adenocarcinoma. ${ }^{9}$ The aim of this study is to investigate gastric epithelial cell kinetics at different stages in the progression from normal mucosa to gastric carcinoma and to assess the role of $H$ pylori in this progression.

\section{Methods}

Biopsy specimens from 155 subjects, attending the endoscopy clinics of the Meath and Adelaide hospitals, Dublin, Ireland with dyspeptic symptoms were studied. Subjects with a history of gastrointestinal cancer excluding gastric cancer, adenomatous polyps, $H$ pylori eradication therapy, non-steroidal anti-inflammatory drugs (NSAID) or antibiotic therapy in the previous three months were excluded from the study.

Diagnosis was made at endoscopy and confirmed by histological examination, CLO test, Gram stain, and culture. Subjects were assigned to one of five study groups based on histological findings. Group 1: macroscopically and microscopically normal mucosa, $H$ pylori negative, group 2: type $\mathrm{B}$ gastritis, $H$ pylori positive, group 3: atrophic gastritis, group 4: intestinal metaplasia, group 5: gastric adenocarcinoma. The diagnosis of gastric adenocarcinoma was further classified as intestinal or diffuse type according to the Lauren classification. ${ }^{10}$ The gastric carcinomas were also classified according to the Goseki method of histological classification, which relates the histological type of gastric cancer to the mode of extension. ${ }^{11}$
Correspondence to: Professor C O'M

Gastroenterology, Meath Hospital, Heytesbury Street, Dublin 8, Ireland. 24 July 1995 
TABLE I Demographic profile of all study groups

\begin{tabular}{lclllc}
\hline Study group & No & $\begin{array}{l}\text { Age } \\
\text { mean }(S D)\end{array}$ & $\begin{array}{l}\text { Age range } \\
(y)\end{array}$ & Male:female & $\begin{array}{l}\text { H pylori status } \\
\text { pos:neg }\end{array}$ \\
\hline Normal & 32 & $44(16)$ & $23-81$ & $12: 20$ & $0: 32$ \\
H pylori positive gastritis & 83 & $45(16)$ & $17-84$ & $41: 42$ & $83: 0$ \\
Atrophic gastritis & 9 & $72(13)^{\star}$ & $43-86$ & $2: 7$ & $6: 3$ \\
Intestinal metaplasia & 19 & $59(15)^{\star}$ & $32-81$ & $13: 6$ & $6: 13$ \\
Gastric cancer & 12 & $70(9)^{\star}$ & $53-82$ & $10: 2$ & $3: 9$ \\
\hline
\end{tabular}

${ }^{\star} \mathrm{p}<0.05$ when compared with normal controls. The mean age of subjects with precancerous lesions and gastric carcinoma was significantly older than subjects with $H$ pylori positive gastritis alone or normal mucosa.
Endoscopies were carried out between 9 am and 12 noon to control for diurnal variation. Seven antral mucosal pinch biopsy specimens were taken from each subject before and after treatment; one for microbiological assessment, one for CLO test (DeltaWest, Bently, Australia), and one for histological assessment. Four antral mucosal biopsy specimens were taken for proliferation analysis from macroscopically normal mucosa away from any macroscopic lesions. These were immediately placed in modified Waymouths medium.

\section{Cell proliferation technique}

Specimens were cultured in Waymouths medium (Flow Labs, Hertfordshire) supplemented with $10 \%$ fetal calf serum, $1 \mathrm{mM}$ glutamine and gentamicin, $50 \mu \mathrm{M}$ bromodeoxyuridine (BrdU) (Sigma, Poole, UK), and $5 \mu \mathrm{M}$ fluorodeoxyuridine (Sigma, Poole, UK). The specimens were incubated in the medium for one hour at $101.3 \mathrm{kPa}$ of pressure in a sealed modular incubation chamber (Flow Labs, Hertfordshire) previously infused with $95 \%$ oxygen and $5 \%$ carbon dioxide at a thermoregulation temperature of $37^{\circ} \mathrm{C}$. The specimens were fixed in Carnoys fixative overnight and embedded in paraffin wax. Immunohistochemical detection of the BrdU incorporation was carried out on $4 \mu \mathrm{m}$ sections using the technique previously described ${ }^{12}$ with a monoclonal antibody to BrdU (Dakopatts, Denmark). Labelled cells were visualised by the diaminobenzidine reaction and lightly counterstained with haematoxylin.

\section{Immunohistological analysis}

A mean of 20 sections were examined for each subject. Only entire gastric pits longitudinally sectioned, visible in their entire length, and greater than 100 cells were analysed. A mean number of 10 well orientated gastric pits were examined for each specimen.

Labelling index per cent (LI\%) was measured by counting the number of BrdU positive cells and expressing the result as a percentage ratio of the total number of cells in a gastric pit. The relative positions of the positive cells in the pit were noted. For cell kinetic evaluation, each gland was divided into five compartments of equal size. The compartments were referred to by the ordinal numbers 1 (apex) to 5 (base) and the LI calculated for each compartment.

\section{Statistical analysis}

The total LI\% and the LI\% per compartment were compared between the study groups. Significance was analysed using Students' $t$ test for unpaired data. $p$ Values less than 0.05 were considered statistically significant.

\section{Results}

One hundred and fifty five subjects were recruited for the study. Thirty two subjects were included in the normal control group, 83 in the $H$ pylori positive gastritis study group, nine subjects in the atrophic gastritis group, and 19 in the intestinal metaplasia study group. Twelve subjects were included in the gastric adenocarcinoma study group. Table I shows the demographic profile and $H$ pylori status of the study groups. Subjects with type C gastritis without $H$ pylori infection were included in this paper as a reference group, the demographic profile of these subjects is previously described. ${ }^{7}$ A subgroup of the $H$ pylori positive gastritis study group has also been previously reported. ${ }^{7}$

Subjects with chronic atrophic gastritis or intestinal metaplasia had an increased epithelial cell proliferation compared with normal mucosa (LI\% mean (SEM): $5 \cdot 14(0 \cdot 6), 4.68$ $(0.3)$ v $3.08(0.2), \mathrm{p}<0.01$, Table II, Figure). The increased proliferation was seen throughout the entire gastric pit including the apex of the pit.

Tissue remote from gastric adenocarcinoma also had an increased epithelial cell proliferation compared with normal controls (LI\%: $6.50(0.5)$ v $3.08(0.2), \mathrm{p}<0.001$, Table II,

TABLE II Gastric epithelial cell kinetics of all study groups

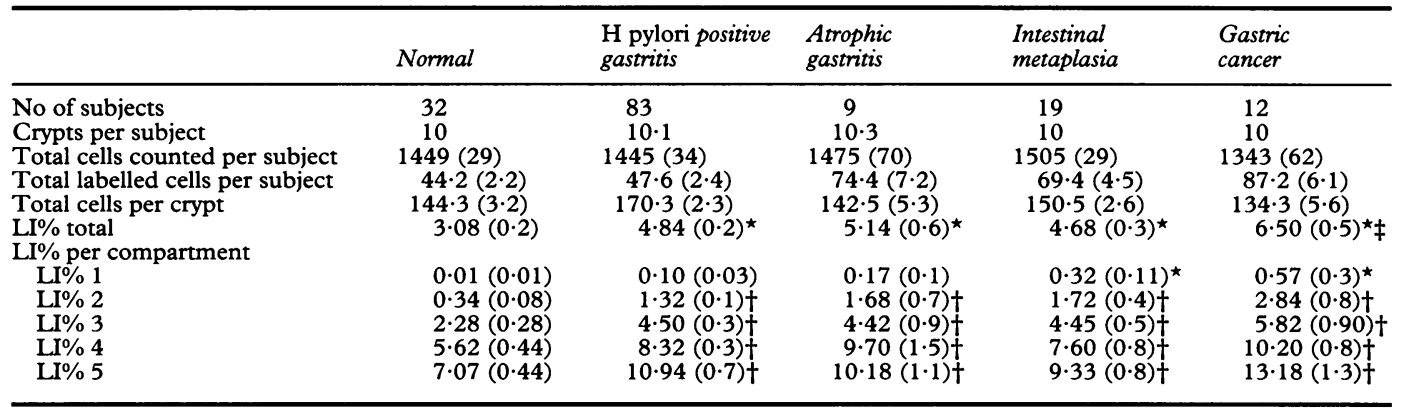

All results expressed as mean $(\mathrm{SEM}) .{ }^{\star} \mathrm{p}<0.01,+\mathrm{p}<0.005$ when compared with normal controls and $H$ pylori negative gastritis. $\neq \mathrm{p}<0.01$ compared with all study groups except atrophic gastritis. All specimens were taken from the antrum remote from $\ddagger \mathrm{p}<0.01$ compared with
macroscopic lesions. 


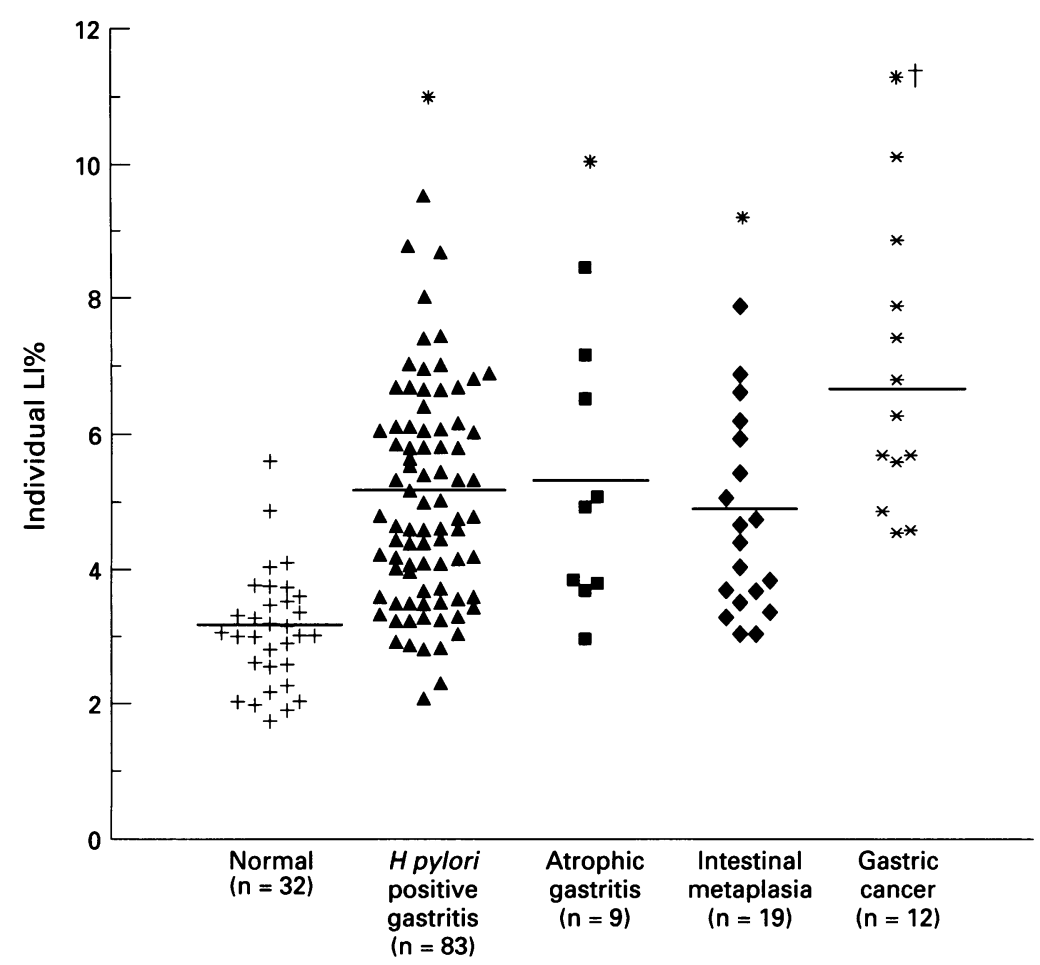

Epithelial cell kinetics of patients in all study groups (total LI\%). Mean total LI\% is also included. Mean LI\% (SD) are as follows; normal $=3.08(0 \cdot 2), \mathrm{H}$ pylori positive gastritis $=4 \cdot 84(0 \cdot 2)$, atrophic gastritis $=5 \cdot 14(0 \cdot 6)$, intestinal metaplasia $=4 \cdot 68(0 \cdot 3)$, gastric cancer $=6.50(0.5) .{ }^{\star} p<0.001$ compared with normal controls, $t p<0.01$ compared with all study groups except atrophic gastritis.

Figure). The increase of proliferation was seen in all compartments of the pit including the apex of the gastric pit. Four of the subjects were diagnosed with diffuse type adenocarcinoma and eight with intestinal type, there was no significant difference in the LI between both groups (LI\%: $6.70(1.03) v 6.36(0.5))$. Similarly there was no significant difference between groups classified according to the Goseki method although subjects with GI $(n=4)$ had a lower proliferation rate compared with both GII $(n=3)$ and GIII $(n=5)$ with proliferation rates of $5 \cdot 34 \%(0 \cdot 4), 7 \cdot 26 \%(1 \cdot 5)$, and $7 \cdot 1 \%(0 \cdot 9)$ respectively.

The presence or absence of $H$ pylori infection did not change the increased epithelial cell proliferation seen in subjects with atrophy, intestinal metaplasia or gastric carcinoma

TABLE III Influence of $\mathrm{H}$ pylori status on gastric epithelial cell proliferation of tissue remote from any macroscopic lesion in subjects with antral gastritis, atrophic gastritis, intestinal metaplasia or gastric cancer

\begin{tabular}{llll}
\hline & Number & LI\% & p Value \\
\hline Antral gastritis & & & \\
H pylori negative & 28 & $3.33(0.2)$ & $\mathrm{p}=0.0014$ \\
H pylori positive & 83 & $4.98(0.2)$ & \\
Atrophy & & & \\
H pylori negative & 3 & $4.98(1.4)$ & $\mathrm{p}=0.519$ \\
H pylori positive & 6 & $5.34(1.8)$ & \\
Intestinal metaplasia & & & \\
H pylori negative & 13 & $4.75(1.6)$ & $\mathrm{p}=0.954$ \\
H pylori positive & 6 & $4.60(1.2)$ & \\
Gastric cancer & & $6.62(2.1)$ & $\mathrm{p}=0.940$ \\
H pylori negative & 9 & $6.44(2.6)$ & \\
H pylori positive & 3 & 6.44 \\
\hline
\end{tabular}

p Value compares subjects with $H$ pylori infection with those without $H$ pylori infection at the time of biopsy. Subjects with $H$ pylori infection and antral gastritis had a significantly higher LI\% compared with those with $H$ pylori negative gastritis (reference group, 10). H pylori infection did not seen to precancerous lesions (atrophy, intestinal metaplasia) or gastric cancer. Data shown as mean (SEM).
(Table III). $H$ pylori positive gastritis had increased epithelial cell proliferation compared with normal controls and subjects with type C gastritis ( $H$ pylori negative) (Table III). This increased gastric epithelial cell proliferation was not significantly different from that associated with chronic atrophic gastritis, intestinal metaplasia or tissue remote from gastric carcinoma.

\section{Discussion}

This study assessed gastric epithelial cell kinetics, using the BrdU immunohistochemical technique. Antral mucosal biopsy specimens remote from macroscopic lesions of subjects with $H$ pylori positive gastritis, precancerous lesions (atrophy and intestinal metaplasia), and gastric carcinoma were studied. Subjects with $H$ pylori gastritis, intestinal metaplasia or atrophic mucosa have an increased epithelial cell proliferation compared with normal mucosa. This increased epithelial cell proliferation is not significantly different from that associated with tissue remote from gastric carcinoma.

Most studies of gastric epithelial cell kinetics have used the tritiated thymidine technique. This technique is time consuming and entails the use of radioactive isotopes. The BrdU immunohistochemical technique has been found to be as accurate as the tritiated thymidine technique. ${ }^{13}$

Quantification of gastric epithelial cell proliferation can be carried out by assessing the number of proliferating cells in the entire gland or in the gastric pit. The assessment of epithelial cell proliferation in the gland entails quantifying proliferating cells in randomised fields. Assessment of gastric pit epithelial cell proliferation is the preferred method of assessment of gastric epithelial cell kinetics and it reflects overall gastric epithelial cell proliferation. In the assessment of epithelial cell kinetics of the gastric pit, the zone of maximum proliferation is in the base of the gastric pit. This has been shown in normal rat $^{14}$ and human mucosa ${ }^{1}$ and has been confirmed by our study.

There is evidence that gastric cancer develops through the progression from normal mucosa to gastric atrophy, intestinal metaplasia to gastric carcinoma. ${ }^{2}$ The pathogenesis of the sequence of events is largely unknown, however, there is a substantial amount of evidence supporting the role of $H$ pylori in gastric carcinogenesis, which comes from many sources. Epidemiological studies have identified a high prevalence of serum antibodies against $H$ pylori in areas of high incidence of gastric cancer. ${ }^{315}$ Histological studies have also identified $H$ pylori associated with precancerous lesions and gastric cancer, although $H$ pylori cannot be found in intestinal metaplastic tissue or adenocarcinoma cells. ${ }^{416}$ $H$ pylori adheres to normal gastric mucosal cells and does not seem to adhere to intestinalised cells, therefore the incidence of $H$ pylor $i$ infection as determined by biopsy methods decreases with progressing preneoplastic lesions. ${ }^{17}$ This was seen in our study. Research 
assessing serum antibody concentrations of subjects with these lesions would suggest that the subjects have probably been infected with $H$ pylori at an earlier stage in the progression. ${ }^{18}$

Previous studies have assessed gastric epithelial cell proliferation in tissue adjacent to and remote from gastric carcinoma and found it increased compared with normal mucosa using the BrdU immunohistochemical technique. ${ }^{19}$ Our study also identified an increased epithelial cell proliferation associated with gastric carcinoma. This increased epithelial cell proliferation was not related to the histological type of gastric carcinoma, intestinal or diffuse. Epidemiological studies have suggested that the intestinal type carcinoma is more influenced by environmental factors than diffuse type carcinoma, which is thought in part to be familial or genetic. ${ }^{2021}$ The role of $H$ pylori in these types of gastric carcinoma is controversial, however, recent studies have identified $H$ pylori as a risk factor for both types of gastric carcinoma. ${ }^{182223}$

Few studies have assessed epithelial cell kinetics in the progression from normal mucosa to gastric carcinoma. Two studies have identified an increased epithelial cell proliferation associated with atrophic gastric mucosa using the tritiated thymidine technique. ${ }^{24} 25$ These studies, however, did not assess the influence of $H$ pylori infection on this changed epithelial cell proliferation. Our study assessed gastric epithelial cell kinetics at all stages in the progression from normal mucosa to gastric carcinoma in a large series of patients and identified an increased epithelial cell proliferation associated with gastric atrophy, intestinal metaplasia, and tissue remote from gastric carcinoma. This finding suggests that increased epithelial cell proliferation is one of the earliest identifiable abnormalities in the development of gastric carcinoma.

This study also showed increased epithelial cell proliferation associated with $H$ pylor infection compared with normal mucosa, which our group has previously described. ${ }^{7}$ This finding has been confirmed by other groups. ${ }^{26-28}$ $H$ pylori infection was associated with an increased total epithelial cell proliferation and an increased number of proliferating cells at the apex of the gastric pit. This is significant as a recent study has shown that cells proliferating near the luminal surface are more susceptible to carcinogens than those proliferating deeper in the gastric gland. ${ }^{29}$ The increase in gastric epithelial cell proliferation associated with $H$ pylori infection was not significantly different from that associated with gastric precancerous lesions. $H$ pylori infection, however, did not seem to influence the changed gastric epithelial cell proliferation in subjects with precancerous lesions or gastric cancer, which suggests that although $H$ pylori has a part to play in early gastric carcinogenesis, it may not have as strong an influence in the later stages of the disease.

In conclusion this study identified increased epithelial cell proliferation associated with gastric precancerous lesions and gastric carcinoma. This was also seen in subjects with $H$ pylori infection in the absence of any precancerous change. $H$ pylori may be the precipitating factor that triggers the genesis of events terminating in gastric carcinoma.

1 Hallissey M, Dunn JA, Ward LC, Allum WH for the British Stomach Cancer Group. The second British Stomach Cancer group trial of adjuvant radiotherapy or chemotherapy in resectable gastric cancer: five-year follow up. Lancet 1994; 43: 1309-12.

Correa P. A human model of gastric carcinogenesis. Cancer Res 198; 48: 3554-60.

3 Eurogast Study Group. An international association between Helicobacter pylori infection and gastric cancer. Lancet 1993; 341: 1359-62.

4 Sasaki N, Momma K, Yamada Y, Tajima T, Shoji N, Handa $\mathrm{N}$, et al. Helicobacter pylori and early gastric cancer: relation to atrophic gastritis in background gastric cancer: relation to atrophic gastritis in background gastric mucosa. European fournal

5 Fiocca R, Luinetti O, Villani L, Chiaravalli A, Cornaggia M, Stella G, et al. High incidence of Helicobacter pylori colonisation in early gastric cancer and the possible relationship to carcinogenesis. European fournal of Gastroenterology and Hepatology 1993; 5 (suppl 2): S2-8

6 Gilvarry J, Leen E, Sant S, Sweeney E, O'Morain C. The long-term effect of Helicobacter pylori on gastric mucosa. European fournal of Gastroenterology and Hepatology 1994; 6: 43-5.

7 Cahill RJ, Sant S, Beattie S, Hamilton H, O'Morain C. Helicobacter pylori and increased epithelial cell proliferation: a risk factor for cancer. European fournal of tion: a risk factor for cancer. European foum

8 Cahill RJ, Xia H, Kilgallen C, Beattie S, Hamilton $H$ O'Morian CA. Effect of eradication of Helicobacter pylori infection on gastric epithelial cell proliferation. Dig Dis $S c i$ 1995; 40: 1627-31.

9 Lipkin M. Biomarkers of increased susceptibility to gastrointestinal cancer: new application to studies of cance prevention in human subjects. Cancer Res 1988; 48: 235-45.

10 Lauren $P$. The two histological types of gastric carcinoma: diffuse and so-called intestinal type carcinoma. Acta Pathol Microbiol Scand 1965; 64: 31-43.

11 Goseki N, Takizawa T, Koike M. Differences in the mode of the extension of gastric cancer classified by histological type: a new histological classification of gastric carcinoma. Gut 1992; 33: 606-12.

12 Cahill R, O'Sullivan KR, Mathias PM, Beattie S, Hamilton $H$, O'Morain C. Effects of vitamin antioxidant supplementation on cell kinetics of patients with adenomatous polyps. Gut 1993; 34: 963-7.

13 Lacy R, Kuwayama H, Cowart KS, King JS, Deutz AH, Sistrunk S. A rapid accurate immunohistochemica method to label proliferating cells in the digestive tract. A comparison with tritiated thymidine. Gastroenterolog 1991; 100: 259-62.

14 Tsujii M, Kawano S, Tsujii S, Ito T, Nagano K, Sasaki Y, et al. Cell kinetics of mucosal atrophy in rat stomach et al. Cell kinetics of mucosal atrophy in rat stomach induced by long-term administra

15 Fox J, Correa P, Taylor NS, Zavala D, Fontham E, Janney $\mathrm{F}$, et al. Campylobacter pylori-associated gastritis and immune response in a population at increased risk of gastric carcinoma. Am $\mathcal{F}$ Gastroenterol 1989; 84 $775-81$.

16 Clarkson KS, West KP. Gastric cancer and Helicobacter pylori infection. f Clin Pathol 1993; 46: 997-9.

17 Loffield R, Willems L, Flendrig JA, Arends JW. Helicobacter pylori and gastric cancer. Histopatholog 1990; 17: 537-41.

18 Asaka M, Kimura T, Kato M, Kudo M, Miki K, Ogoshi K, et al. Possible role of Helicobacter pylori in early gastric et al. Possible role of Helicobacter pylori in ea

19 Britio M, Filipe MI, Morris RW. Cell proliferation study on gastric carcinoma and non-involved gastric mucosa using a bromodeoxyuridine (BrdU) labelling technique. Eur $\mathcal{F}$ Cancer Prev 1992; 1: 429-35.

20 Munoz N, Correa P, Cuello C, Duque E. Histologic types of gastric cancer in high- and low-risk area. Int $\mathcal{\exists}$ Cancer 1968; 3: 809-18.

21 Correa P, Haenzel W. Epidemiology of gastric cancer. In: Correa P, Haenzel W, eds. Epidemiology of cancer of the digestive tract. The Hague, the Netherlands: Martinus Nijhoff, 1982: 58-84.

22 Parsonnett J, Friedman GD, Vandersteen DP, Chang Y, Vogelman $\mathrm{JH}$, Orentreich $\mathrm{N}$, et al. Helicobacter pylori infection and the risk of gastric cancer. $N$ Engl f Med 1991; 325: 1127-31.

23 Nomura A, Stemmermann GN, Heilbrun LK, Salkeld RM, Vuilleumier HP. Helicobacter pylori infection and gastric carcinoma among Japanese Americans in Hawaii. N Engl carcinoma among Japanes

24 Deschner E, Winawer SJ, Lipkin HT. Patterns of nucleic acid and protein synthesis in normal human gastric mucosa and atrophic gastritis. $\mathcal{f}$ Natl Cancer Inst USA 1972; 48: 1567-74.

25 Biasco G, Paganelli GM, Brillantti S, Lalli AA, Brandi G, Terranova A, et al. Cell renewal and cancer risk of the 
stomach: analysis of cell proliferation kinetics in atrophic gastritis. Acta Gastroenterolog Belg 1989; 52: 361-6.

26 Brenes F, Ruiz B, Correa P, Hunter F, Khamakrishnan T, Fontham E, et al. Helicobacter pylori causes hyperproliferation of the gastric epithelium: pre and post eradication indices of proliferating cell nuclear antigen. $A m \mathcal{J}$ indices of proliferating cell
Gastroenterol 1993; 88: 1870-5.

27 Lynch DAF, Mapstone NP, Clarke AMT, Sobala GM, Jackson P, Morrison L, et al. Cell proliferation in Helicobacter pylori associated gastritis and the long-term effect of eradication therapy [Abstract]. Gut 1994; 35 (suppl 2): S4.

28 De Koster E, Buset M, Fernandes E, Martin N, De Reuck $\mathrm{M}$, Deprez $\mathrm{C}$, et al. Influence of $\mathrm{Hp}$ and gastritis on gastric antum and corpus mucosal cell proliferation [Abstract]. acta Gastroenterolog Belg 1993; 56: 61

29 Sørbye H, Kvinnsland S, Svanes K. Effect of salt induced mucosal damage and healing on penetration of $\mathrm{N}$-methyl$\mathrm{N}$-nitrosoguanidine to proliferative cells in the gastric mucosa of rats. Carcinogenesis 1994; 15: 673-9. 